\title{
High volume surgery, flood myths, cancer, and minions
}

\author{
F.M. Riegler
}

Published online: 13 November 2015

(C) Springer-Verlag Wien 2015

Dear reader,

Welcome to the present issue of European Surgery. Going in line with the notion to foster the open-minded approach and novel developments, the spectrum of articles and contributions addresses minimally invasive surgery for the treatment of colorectal cancer, gastric cancer, esophageal disorders, management of liver regeneration, urinary tract carcinoma, diaphragmatic malignancy, and vitamin D metabolism. Most importantly, the papers focus on the life quality issue and the patient selection criteria for respective treatments. The authors are to congratulated for their patience, long-standing experience, and enthusiastic highly motivated approach towards the wide-range of diseases and personalized treatment modalities. Most importantly, the papers center their focus on the elimination of causes for the impairment of the life quality and productivity of those affected. Individuals wish to live in perfect well-being.

In addition to the beautiful and colorful sequence of masterpieces of minimally invasive and open surgery, this issue includes a novelty: a consensus paper in that form has not been published in European Surgery before. Usually physicians in the EU base their guidelines on recommendations coming from abroad. However, diseases, their presentation, coverage of therapies by the social security system may vary between EU countries and abroad. Therefore, it seems justified to consider tailored treatment recommendations for each continent and country. Thus, a group of highly motivated Austrian gastroenterologists, surgeons, and pathologists set together to define the first nationwide inter-disciplinary

F.M. Riegler $(\square)$

Reflux Medical,

Mariannengasse 10/9,

1090 Vienna, Austria

e-mail: martin.riegler@refluxmedical.com recommendation for the treatment of Barrett's esophagus (a premalignant condition, caused by gastroesophageal reflux). Their findings are summarized in the consensus statement paper, which is published in the present issue of European Surgery. Finally, we hope that the article will motivate experts from other specialities (oncology, bariatric, endocrine, vascular, transplant, plastic, trauma and orthopedic, head and neck, and dental surgery) to open their minds and spread their ideas to launch similar projects in their respective fields.

\section{Hunter gatherer attitude}

Conceptually, surgery mirrors and lives the hunter gatherer aspect of the human being. Most importantly this notion is well-taken by oncologic surgery. The highly dangerous lion hides within the human body. Modern imaging helps to localize the lion. Biopsy sample tissue harvest proves that the lion in fact is a lion. Then surgical strategy aims to assess the conduct of the hunt and to define the weapons implied (chemotherapy, radiation therapy). Finally, the sick persons is positioned within the operation theatre. And then it has to happen. In order to heal, the hunter (surgeon) inflames his skilled spectrum of expertise and experience, spreads out the full sweat and blood to catch and kill the lion (but not his land). Following the resection, the specimen is forwarded to the hunter of morphology (pathologist) for the assessment of tumor clearance (R0, T-stages, $p<0.0001$ ). Thus, the hunters gather their cases and increase their volume. Sometimes it may happen that the increase of case volume parallels with an increased body volume of the hunter (surgeon, pathologist body mass index, waisthip ratio lacks the logos). Numbers count. Therefore, the medical arena coined the term: high volume surgery. Here we go. 
Modern man became the remote and permanent application of the computer technology. The fruits of the technical revolution including the loom, factory, and mill have been replaced by the cell phone tablet technology, which dominates man and fits into the palm of a hand. There it stays and controls all aspects of life: business, privacy, work, sleep, eating, sports, motion, emotional life, heartbeat, blood pressure, digestion, love, and even reproduction. However, it seems that man has forgotten about the possibility to throw away the device, at least for some hours per week (Fig. la, b ). In harsh contrast to that, the hunter gatherer society used to watch the freeway full screen landscape during daytime and the heavens and the stars during the night. Furthermore, the hunter gatherers mirrored heaven, stars and zodiacs on the earth in form of agriculture, architecture, and myths. These observations have been turned into knowledge and wisdom and evolved as the wells for the conduct of reasoning of our present world (pseudo-monotheistic models). Unfortunately, modern technologies and the domination of artificial lighting impair the vision of the nocturnal skies. As a consequence, we have lost the senses for the information provided out there in space for us. Thus, we are not open to the legacies of previous civilizations. Most importantly, it seems that the information IS out there for us. Remains to be questioned, in as much this lack (limos) of legacy contributes to the psychological aspects of life and disease? May this be the reason for our current insecurity? What is going to come?

\section{Message of a lost civilization}

Based on the work of Graham Hancock, John Anthony West, Robert Bauval, and Robert Schoch $[1,2]$, an increasing body of evidence evolved to suggest that there in fact exists the historical basis of the so-called flood myths, which have been developed and told for thousands of years all over the world (Egypt, Mesopotamia, Indus valley, Persia, Mid-, South America, Pacific Ocean). The myths have come down to us in form of the Gilgamesh epos, Vedas, Upanishads, Old testament (Tora), Pyramid texts of the old Kingdom in Egypt, Popol Vuh of the Mayas, Norse mythology where there is provided uniform information about the "first time" after the "great flood" $[1,2]$.

The essence of the myths suggests a highly developed "lost" civilization before the end of the last ice age (more than 15,000 years ago), which has been eradicated by the great flood. Survivors of the "lost" civilization are suggested to have been spreading out over our planet to transmit their highly developed knowledge and skills to the hunter gatherer societies. Within the myths, the survivors and mentors for know how transfer are remembered in the form of gods: Osiris, Oannes, Yima, Viracocha, Quetzalcoatl, Odin, Zeus, Baal, and many more. The spectrum of know how transfer is well-documented in form of the high-tech precision megalithic arts and architectures all over our planet: Giza in Egypt, Göbekli Tepe in Turkey, Gunung Padang in Indonesia, Sacsayhuaman, Caral in Peru, Tiahuanaco in Bolivia, Teotihuacan in Mexicao, and Easter Island in the Pacific Ocean. The common notion of these megaliths is: the older, the larger, and the more precise. Finally, gigantic line drawings translating ancient astronomical knowledge have been left for us in the desert of Nazca, Peru.

\section{Precession times the world}

The semiotic and astronomical analysis indicates that the above cultures most probably originate from a common precursor ("the survivors of the lost civilization") and it seems to be justified to re-date the age of their architecture to 9,000-10,000 years before present. In addition, mathematical analysis indicates that the builders of these megalithic cultures have been well-educated about precession $[1,2]$. In addition to moving around the sun and around its own axis, the axis of our planet follows a movement termed precession.

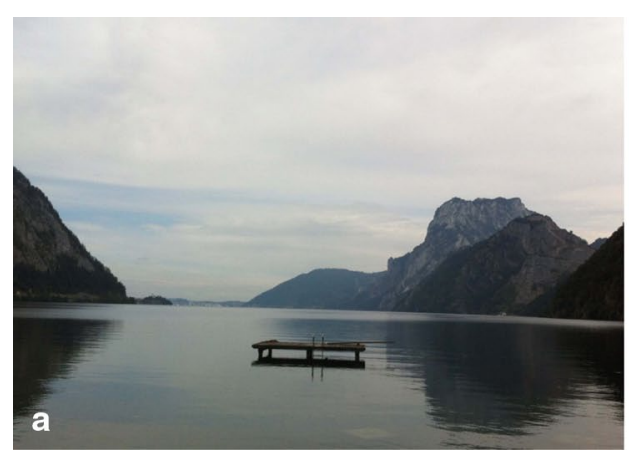

Fig. 1 The image mirrors the different natures of perceivable moods ranging from silence $\mathbf{a}$ to motion $\mathbf{b}$. The image should stimulate to take a break from technology dominated way of life to find time and space for the beauties of our planet, as outlined in the text. The image has been obtained at "Leber-

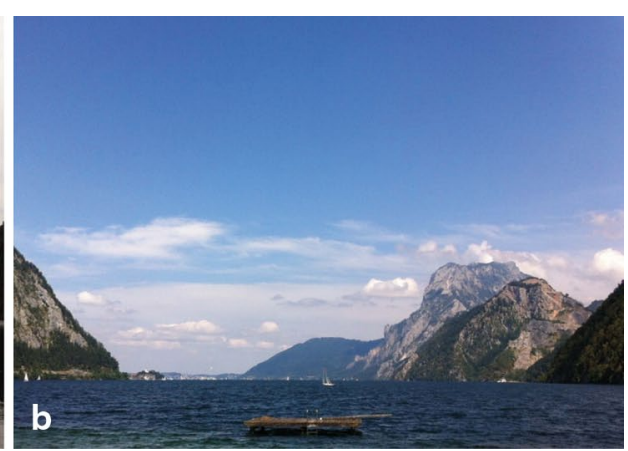

kas", Ebensee, shore line of lake Traunsee, Upper Austria. In the rear right arises the Gmundnerberg. All mountains hide a complex system of caves, tubes, labyrinths, rivers, and lakes. Image obtained by the author in August 2015, using iPhone technology 
Precession is the wobble movement of the axis of the earth, which has been mirrored by Yggdrasil, the gigantic ash of the norse mythology [1]. The entire course for one precession cycle takes about 26,000 years (i.e., the "great year" in many ancient myths). Thus, it moves about one degree every 72 years. As a consequence of precession, the sun does not always rise against the same constellation of zodiac during spring and autumn equinox (day and night have the same length all over the globe) and at summer (longest day) and winter solstice (shortest day). Due to precession the sun arises against one "house" (beth el, hebrew "house of god") of the zodiac for approximately 2160 years. Currently, the sun is "moving" from fish to aquarius during the spring equinox. It seems that the zodiac against which the sun rises at spring equinox determines the icon of an epoch, that is, lion in the time of the sphinx and Göbekli Tepe, bull in the old kingdom of Egypt and the Crete culture at Knossos, Aries in the New Kingdom in Egypt and the time of the formation of Israel (Tora), fish since the last 2000 years of Christianity.

The lost civilization seems to have been eradicated by a gigantic comet which mainly impacted on the North American ice cap and was the cause for the young dryas (12,000-10,000 years before present) [2]. As a consequence, the North American ice cap collapsed and delivered an acute flood, which caused a global $50-150 \mathrm{~m}$ sea level rise over a period of 100-500 years. In addition, the skies darkened and the temperatures decreased. Based on glacial ice examination in Greenland and nano dia- mond assessment (i.e., the mark of a comet impact) all over the world, it seems justified to assume that the comet came back with a smaller impact 2000 years later. During this period of 1000-2000 years, the earth was cold and dark, as reported in the ancient myths, and experienced the extinction of many species. Within the myths, the comet impact is remembered as the Ben Ben Phoenix in ancient Egypt, the fire snakes in tales of the NorthSouth American Indians and many other regions of the earth. After the end of the young dryas (10,000-8,000 years before present) the global temperatures rose and the climate became moderate and similar to the present condition. These climatic changes fostered the ambitions of the survivors of the great flood (comet impact, cataclysm, young dryas) and helped them to achieve their goal: the know how transfer to OUR ancestors. Thus, the end of the young dryas opened as the meaningful well of origin for our present culture and history (Fig. 2a, b).

Remnant enclosures of the "lost civilization have been found 50-150 m below sea level offshore India, Japan, and the Pacific coast of the Americas. Most importantly, recent excavations of the T-like structures in Göbekli Tepe, Turkey, and the large pyramid in Gunung Padang, Indonesia, assessed an age of 12,000 and 14,000-24,000 years, respectively. Before the young dryas induced sea level rise Indonesia was a large subcontinent called Sundaland. Thus, it seems that Indonesia may represent a "good" candidate for Plato's Atlantis [2]. Remains to

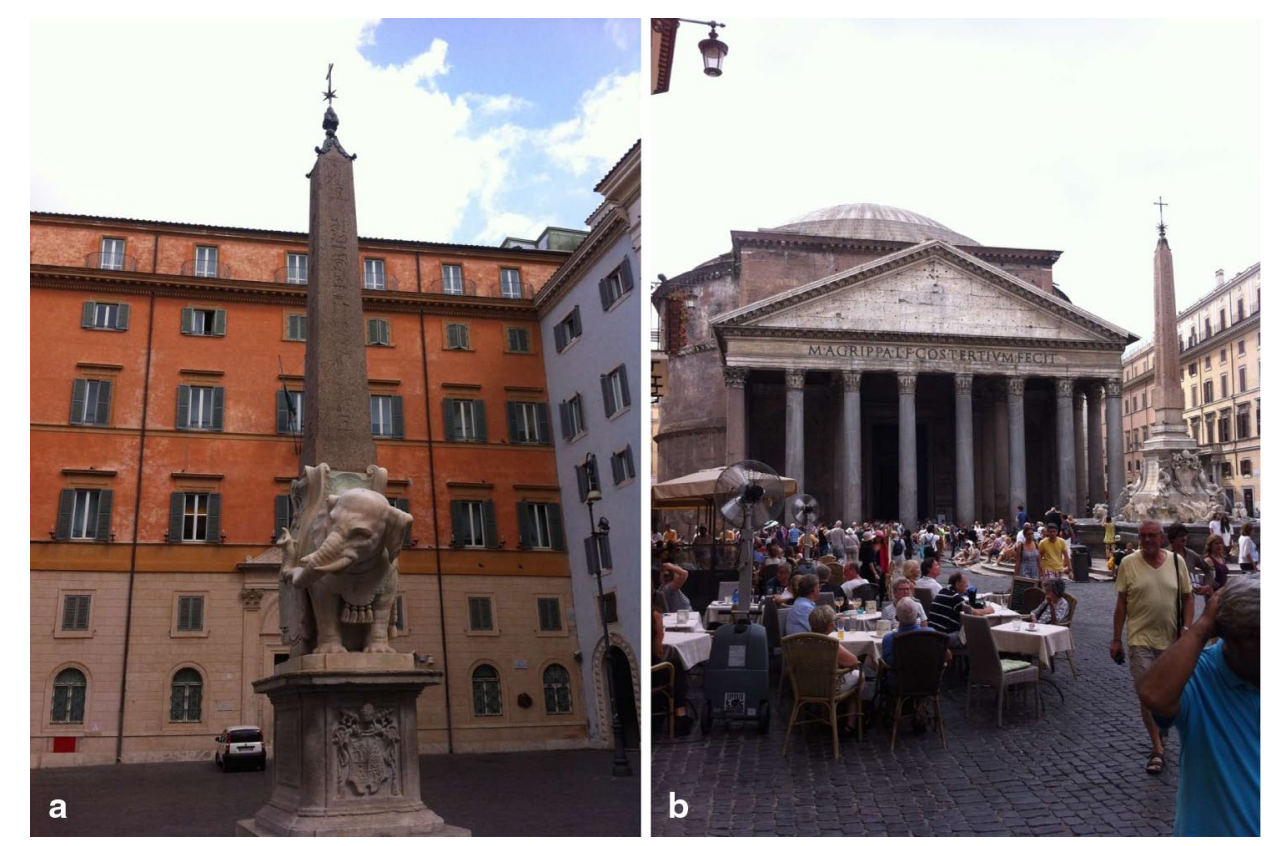

Fig. 2 a Old Egyptian obelisk, initially erected in Sais 587 B.C., transferred to Rome to be placed in front of the Isis temple during the reign of Caesar Augustus, then lost, found and positioned above the Bernini Elephant at the Piazza Minerva in Rome, adjacent to the pantheon around 1600. b Obelisk at Piazza della rotonda, transferred from Egypt to Rome to be placed in front of the pantheon (age: roman time). The com- position and orchestration of the obelisks and the pantheon mirror the myths of a lost civilization, as outlined in the text. All essentials of recent believe and wisdom are fused into the form of beautiful art, through which speaks the cross talk between heaven and earth, concepts of resurrection, transition, and holistic approaches towards being. Image obtained by the author in August 2015, using iPhone technology 
Table 1 Parallels between cancer disease and the great flood

\begin{tabular}{|l|l|l|}
\hline $\begin{array}{l}\text { Prior to the event } \\
\text { Time before the flood }\end{array}$ & $\begin{array}{l}\text { Event } \\
\text { Comet impact/great } \\
\text { flood }\end{array}$ & After the event \\
\hline Time before cancer & Cancer diagnosis & $\begin{array}{l}\text { Time after cancer } \\
\text { diagnosis }\end{array}$ \\
\hline Collect perceptions & Allegory/metaphor & $\begin{array}{l}\text { Explanation, } \\
\text { interpretation, } \\
\text { justification }\end{array}$ \\
\hline $\begin{array}{l}\text { aBoth events, the great flood, and cancer diagnosis are retrospectively } \\
\text { evaluated in order to find an explanation/interpretation for their cause } \\
\text { (ethical, moral, geological, genetical). Thus global geological events, climate } \\
\text { changes, and diseases may continue to exist in the common memory of our } \\
\text { civilization to justify ourselves, as described in the text }\end{array}$ \\
\hline
\end{tabular}

be questioned why a surgeon should bother about the young dryas and the lost civilization?

\section{Link between flood myths and cancer}

First, the above considerations indicate that any highly developed culture is not inviolable against comet impacts, destruction, and extinction. The universe and nature are more potent than we are. The capability to build atomic bombs, fly vehicles to the moon and other planets, remote ourselves as computer software applications means that we are ready as long as it, the being, allows us to do so. What has happened 12,000-10,000 years ago, may happen again, at any time, even within the near future and extinguish our culture. Here, we should start to reason how to behave with our planet, with our nature, and ourselves. Let us decode the signs: it lies within the nature of man.

Second, imagine the flood myths aim to contain another hidden knowledge. Imagine you get the diagnosis of having cancer (Fig. 3). This reality will hit you like a major comet impact, melt your ice caps (how could it happen that you froze them?) and subside yourself under the cataclysmic flood of emotions and helplessness. And as with the ancient flood myths you will define the time before and after the flood, that is, the diagnosis (Table 1). Going in line with the ancient flood myths you will try to search out for causes to justify a reason for cancer development in the times before the diagnosis, before YOUR great flood. Remains to be questioned the essence of the myths? May their message incorporate a legacy of major importance and significance for us TODAY? May the understanding of the myths, the stories about great floods of the planet-the great floods affecting an individual-symbolize the motivation for a strategy towards wisdom to prevent upcoming cataclysm and cancer?

To me the central theme is well-taken by the concept of the muse. As outlined by Roul Schrott [3], following an important cultural transfer, the ancient greeks took up the concept of the muse from the cultures at the Levante. There the goddess $M u s(u) n i$ personalized the principle of regulation, assembling, ordering, commanding and,

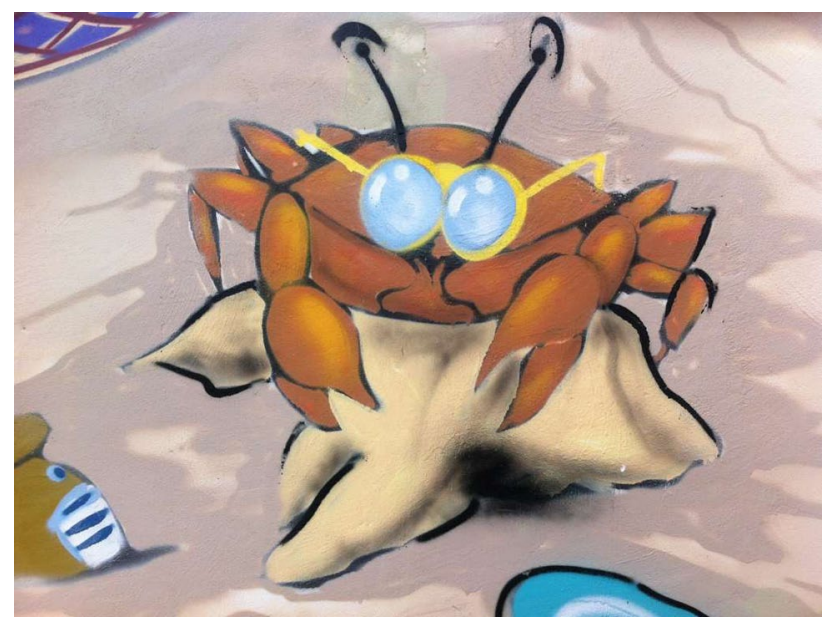

Fig. 3 The image cartoons the idea of the author that cancer mirrors the concept of the great flood, as outlined in the text. Behind its glasses hide possible meanings regarding the justification for the disease (why did one's ice caps freeze?), which divides the individual life in the epoch before and after the flood (i.e., cancer diagnosis). Image obtained by the author in Nettuno, Italy, August 2015, using iPhone technology

most important, discipline. Thus, disciplined lifestyle including healthy nutrition (avoid consumption of concentrated sugars, alcohol, cigarette smoking), regular sports, and adequate ethical behavior (respect against our planet, nature, and ourselves) may in fact contribute to avoid cataclysms and cancer development.

\section{Minions: the wisdom code of legacy (BU)}

Conceptually, the legacy of the flood myths aims to motivate us to over think our present way and conduct of life. Maybe we should outbalance the lack (limos) of time without the cell phone, tablet, and laptop. Even when we, as surgeons, hold the cancer within the protective shadow of our skilled hands, as we do during a radical tumor resection, we should be aware of the fact, that the flood may hit us, too. We should be more sensitive to the signs of the landscape, heavens, the earth, the sun, moon, stars and zodiacs (Fig. 2a, b). Every face we meet contains the fundamental message of the entire cosmos. Going in line with the three stars of the Orion (Osiris) we should focus to outbalance the lack (greek limos) of gratitude, humility, and veneration. Furthermore, we should remind ourselves to abandon greed, envy, and hate.

Otherwise, we may become the uncritical exploited executors of an invisible industry driven despotism, as mirrored by the recent cartoon figures termed Minions [4]. At first sight, these happy, friendly figures tune out some sort of security, cosiness similar to our childhood. Due to the lack (limos) of security in our present world, the Minions are highly attractive even for adults. In contrast to that, the Minions seem to transport a hidden, deeper symbolisms. May it just be by accident, that the Minions (english: loyal servants!!!) perfectly mirror 
the uniform outfit of the brain-washed loyal servants and workers in the war fare factories and concentration camps of the fascistic, national-socialistic, and stalinism epochs of the recent century? Or does it mean, that we still live in such a period without knowing it? Hidden under the cover of cool runnings blue jeans easy living? Does the cancer hide? Is the flood ready to explode? Are we the Minions, the loyal servants of an unknown global power? Having eaten up the fish, are we looking out for a new leader in the "house of aquarius"? Now we are at turn to read the signs. Remains to be questioned if the coloring and dressing of the Minions (i.e., yellow figures, wearing blue jeans) happened by accident or if the artists wish to tell us a deeper message: their esteem regarding the political configuration and military power supposed to rule our planet in the future?

Be motivated to clear the sky and let your sun shine. Become focused for the essential. Power your existence to cheer up, enjoy your time, have high case volumes for getting known, important and indestructible, reputation counts $(€)$ : be you (BU).

Martin Riegler

\section{Acknowledgments}

The above editorial is dedicated to all mentors of openminded reasoning for the salvage of the outstanding beauty of our planet and ourselves. Only with love in your eyes, humility in your hands, patience in your heart, may your efforts transform into successful treatment and support of your patients.

\section{Conflict of interest}

The author declares that there exists no conflict of interest.

\section{References}

1. Hancock G. Fingerprints of the gods. The evidence of earth's lost civilization. New York: Three Rivers Press; 1995. 411-16.

2. Hancock G. Magicians of the gods. The forgotten wisdom of earth's lost civilization. London: Hodder \& Stroughton Limited; 2015. 425-50.

3. Schrott R. Hanser: Hesiod Theogonie; 2014. 97-8.

4. https://de.wikipedia.org/wiki/Minions 